\title{
PENERAPAN KONSEP GEOTAGGING PADA APLIKASI TANGGAP DARURAT BENCANA BERBASIS ANDROID
}

\author{
Nunu Nurdiana, ST. M.Kom ${ }^{1}$, Asep Rachmat, ST., MT. ${ }^{2}$, Dian rahmat nataatmaja hadi sugandi, S.kom ${ }^{3 *}$ \\ 1,2 Program Studi Informatika Fakultas Teknik Universitas Majalengka \\ Jln. KH. A. Halim No. 103 Majalengka-Jawa Barat-Indonesia \\ ${ }^{1}$ nunu.nrd@gmail.com \\ 2asep18rachmat75@gmail.com \\ 3dian.rahmat74@gmail.com
}

\begin{abstract}
Abstrak - Saat ini aplikasi mobile berbasis android telah banyak digunakan seiring semakin banyaknya perangkat smartphone android. Namun penyampaian informasi khususnya informasi bencana di majalengka masih saja belum tersampaikan dengan baik. Seiring dengan hal tersebut, maka dibutuhkan aplikasi pendukung untuk menyampaikan informasi bencana yang lengkap dan akurat. Penelitian ini dilakukan untuk perancangan aplikasi tanggap darurat bencana majalengka dengan konsep Geotagging berbasis android. Pengumpulan datanya menggunakan observasi, studi pustaka dan wawancara dengan metode pengembangan sistem menggunakan RUP, Kemudian data diimplementasi untuk dapat diaplikasikan pada aplikasi android. Pengimplementasian aplikasi android ini dirancang menggunakan bahasa pemrograman Java dengan aplikasi pendukung android studio versi 3. Pengujian aplikasi menggunakan blackbox, didapatlah aplikasi tanggap darurat bencana yang bisa digunakan untuk melaporkan kejadian bencana dari smartphone android dengan memberikan laporan bencana yang cukup jelas karena terdapat foto bencana, informasi mengenai titik lokasi bencana, keterangan bencana dan peta yang bisa diakses melalui google maps.
\end{abstract}

Kata kunci-Aplikasi android, Tanggap darurat bencana, Geotagging, firebase, android studio.

\section{Pendahuluan}

Tanggap darurat bencana adalah serangkaian kegiatan yang dilakukan dengan segera pada saat kejadian bencana untuk menangani dampak buruk yang ditimbulkan, yang meliputi kegiatan penyelamatan dan evakuasi korban, harta benda, pemenuhan kebutuhan dasar, perlindungan, pengurusan pengungsi, penyelamatan, serta pemulihan dari trauma, iklim indonesia yang terkadang ekstrim khususnya kabupaten majalengka dapat menyebabkan majalengka menjadi rawan bencana sehingga membutuhkan respon yang cepat ketika di suatu daerah terjadi bencana.

Bencana menurut Undang-undang Nomor 24 Tahun 2007 Tentang Penanggulangan Bencana menyebutkan definisi bencana sebagai berikut: Bencana adalah peristiwa atau rangkaian peristiwa yang mengancam dan mengganggu kehidupan dan penghidupan masyarakat yang disebabkan, baik oleh faktor alam dan/atau faktor nonalam maupun faktor manusia sehingga mengakibatkan timbulnya korban jiwa manusia, kerusakan lingkungan, kerugian harta benda, dan dampak psikologis.[3]

Penyampaian informasi menganai kejadian bencana di kabupaten majalengka memiliki kendala dikarenakan keterbatasan aplikasi pendukung dan kekurangtahuan masyarakat harus melaporkan kemana sehingga petugas terkait yang berwenang untuk menangani hal tersebut tidak bisa segera merespon kejadian tersebut, selain itu untuk penyampaian informasi mengenai bencana dari petugas terkait terhadap masyarakat kurang tersampaikan secara menyeluruh maka dari itu harus adanya inovasi aplikasi pendukung untuk tanggap darurat bencana di kabupaten Majalengka.

Aplikasi pendukung yang digunakan untuk penyampaian informasi bencana haruslah memiliki inovasi terbaru salah 
satunya adalah Geotagging sehingga apabila terjadi bencana masyarakat bisa segera melaporkan kejadian tersebut menggunakan aplikasi android dengan memberikan foto kejadian bencana, keterangan mengenai bencana, karena aplikasi pendukung menggunakan konsep Geotagging maka ketika masyarakat melaporkan bencana petugas terkait akan mendapatkan titik kordinat lokasi kejadian sehingga bisa segera direspon dengan cepat agar meminimalisir korban jiwa dan korban harta.[4]

Geotag atau Geotagging merupakan suatu proses penambahan informasi geografis pada berbagai macam media, seperti foto, video, website, dan jejaring sosial. Nama lain dari Geotagging pada media berupa foto adalah GPS Photo Tagging dan produknya bernama foto geotag. Tujuannya adalah untuk memberikan informasi keruangan atau keterangan tempat yang berkaitan dengan media tersebut. Pada umumnya informasi geografis yang diberikan adalah berupa informasi koordinat lintang dan bujur suatu tempat. Untuk melakukan Geotagging dengan media foto diperlukan dua perangkat sekaligus, yaitu perangkat sensor kamera dan perangkat GPS (Global positioning system). Sensor kamera digunakan untuk merekam data foto dan GPS digunakan untuk merekam posisi koordinat lintang dan bujur titik exposure foto.[1]

\section{Metodologi Penelitian}

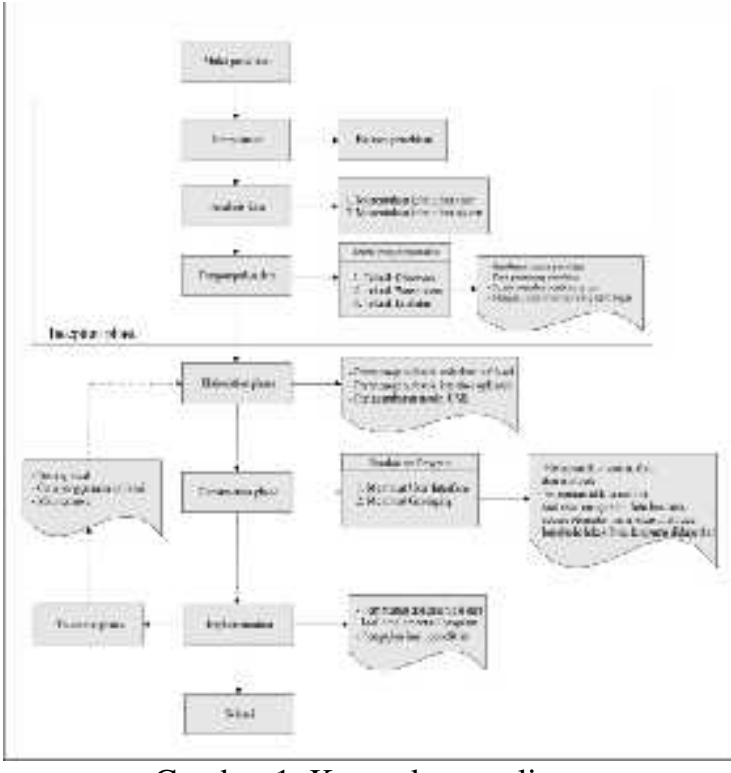

Gambar 1. Kerangka penelitan

Metodologi yang diterapkan pada penelitian ini adalah dengan Rational Unified Process (RUP), Ada beberapa tahapan dalam melakukan penelitian ini, akan dijelaskan dibawah ini:

\section{A. Inception Phase}

Pada tahap ini penulis menentukan batasan peneletian atau ruang lingkup dari penelitian, kendala, Analisis data dan teknik pengumpulan data yang didapatkan dari hasil konsultasi dengan pengguna yang kemudian didefinisikan secara rinci dan berfungsi sebagai spesifikasi sistem.

\section{1) Identifikasi Masalah}

Permasalahan yang terjadi pada sistem atau cara pelaporan ketika terjadi bencana disuatu daerah di majalengka, sebagai berikut:

a. Kesulitan komunikasi dan penyampaian informasi bencana antara masyarakat dengan petugas terkait.

b. Belum ada sistem pendukung untuk tanggap darurat bencana.

\section{2) Metode Pengumpulan Data}

Metode pengumpulan data yang dilakukan adalah sebagai berikut:

a. Observasi

Pengamatan langsung di tempat penelitian terhadap objek yang akan di jadikan sumber data penelitian yang digunakan penulis dengan mengumpulkan data-data. Dalam hal ini yaitu instansi terkait yaitu BPBD Majalengka dan beberapa daerah di majalengka.

b. Wawancara

Mengadakan tanya jawab secara langsung dengan pihak BPBD Majalengka dan beberapa masyarakat majalengka mengenai permasalahan dari objek penelitian untuk mendapatkan informasi yang akurat.

c. Studi Literatur

Untuk mendapatkan kajian teoritis sebagai dasar teori di dalam melakukan analisis perancangan dari sistem yang sedang berjalan dan menyusun sistem baru yang akan diterapkan.

\section{3) Spesifikasi Kebutuhan Aplikasi}

Aplikasi dapat dijalankan apabila memenuhi standar atau spesifikasi dari kebutuhan aplikasi tersebut, berikut ini adalah spesifikasi yang dibutuhkan untuk menjalakan aplikasi :

a. Spesifikasi Fungsional

- Fungsi Login untuk user,

- Fungsi Daftar untuk user,

- Fungsi Setting profile untuk user,

- Fungsi Tambah laporkan bencana dengan latitude dan longitude,

- Fungsi Logout untuk user.

b. Spesifikasi Non Fungsional

- Perangkat keras

- Perangkat lunak 


\section{4) Analisis Geotagging}

Konsep Geotaging atau geotag adalah sebuah konsep yang digunakan untuk memberikan informasi yang lebih akurat mengenai posisi, konsep geotaging yang diterapkan pada aplikasi ini bermaksud untuk memberikan informasi posisi tempat terjadinya bencana.

Dasar untuk geotagging adalah posisi. Posisi tersebut berasal dari Global Positioning System (GPS) , dan berdasarkan lintang atau bujur sistem koordinat yang menyajikan setiap lokasi di bumi dari $180^{\circ} \mathrm{BB}$ hingga $180^{\circ} \mathrm{BT}$ sepanjang Khatulistiwa dan $90^{\circ}$ utara melalui $90^{\circ}$ selatan sepanjang meridian utama . Ada dua pilihan utama untuk foto geotagging, yaitu menangkap informasi GPS pada saat foto diambil atau melampirkan foto untuk memetakan setelah gambar diambil.

Cara kerja ataupun penerapan konsep Geotagging pada aplikasi tanggap darurat bencana majalengka adalah sebagai berikut :

a. Ketika user berada dilokasi kejadian bencana, maka user bisa melaporkan kejadian bencana menggunakan aplikasi tanggap darurat bencana majalengka, dengan cara masuk ke halaman laporkan bencana,

b. User harus mengambil foto kejadian bencana yang real sebagai acuan atau gambaran mengenai bencana,

c. Titik koordinat beserta nama lokasi kejadian bencana akan secara otomatis terisi, titik ini mengambil koordinat saat foto tersebut diambil, maka user tidak usah bingung mencari nama lokasi dan titik koordinat lokasi bencana,

d. Masukan keterangan mengenai bencana yang terjadi supaya semakin memperjelas kejadian tersebut.

Konsep Geotagging yang diterapkan pada aplikasi ini dirasa sangat efisien dan membantu dalam melakukan proses tanggap darurat bencana karena sekali melaporkan sudah lengkap semua tertera foto, titik koordinat, nama lokasi dan keterangan mengenai bencana tersebut, daripada sebelumnya yang memiliki kesulitan untuk menyampaikan informasi bencana dan harus mencari titik lokasi tersebut sebelum melakukan proses tanggap darurat bencana.

\section{B. Elaboration phase}

Tahapan ini adalah tahapan perancangan (desain) dari sistem yang akan dibuat.

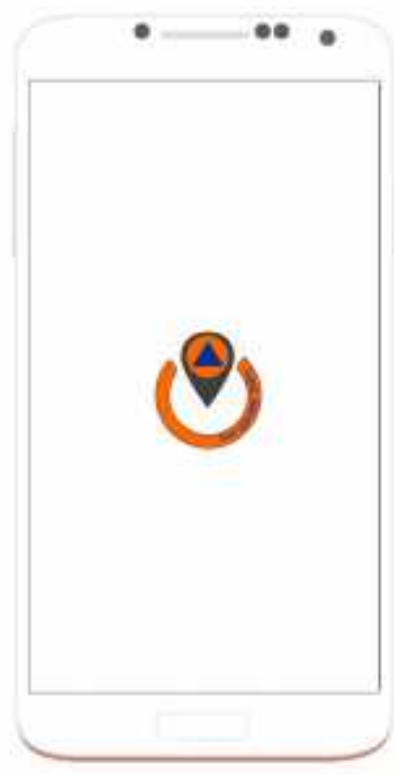

Gambar 2. Perancangan splash screen

merupakan gambaran dari perancangan antarmuka untuk splash screen halaman ini merupakan halaman pemanis dari aplikasi yang dibuat, tempilan akan muncul ketika awal masuk aplikasi.

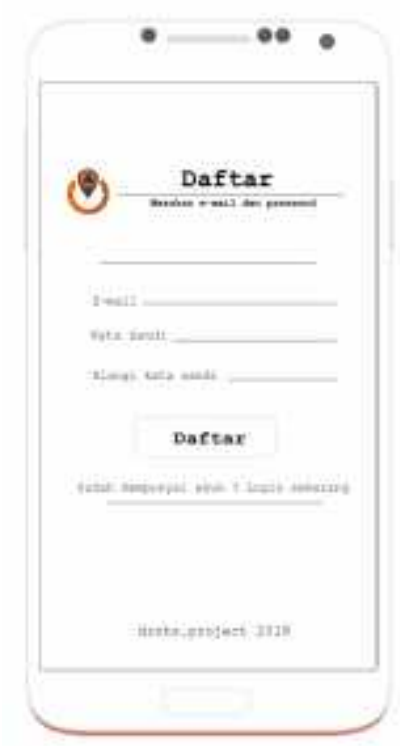

Gambar 3. Perancangan halaman pendaftaran

merupakan gambaran dari perancangan antarmuka untuk melakukan daftar user agar bisa mendapatkan username dan password sehingga bisa mengakses halaman selanjutnya. 


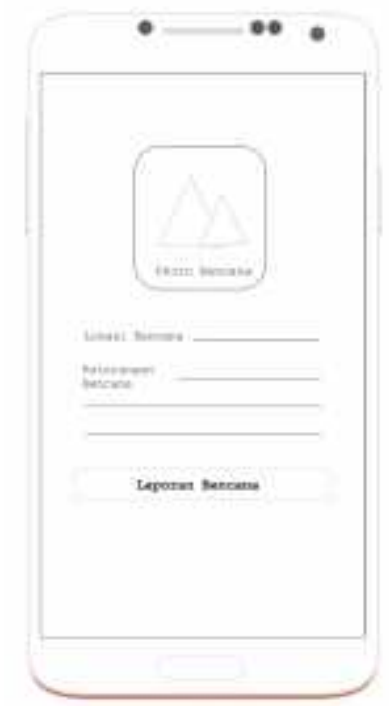

Gambar 4. perancangan halaman melaporkan bencana merupakan gambaran dari perancangan antarmuka untuk halaman melaporkan bencana, halaman melaporkan bencana ini untuk melaporkan kejadian bencana di daerah pengguna aplikasi ini.

\section{HASIL DAN PEMBAHASAN}

Hasil dan implementasi dari aplikasi tanggap darurat bencana majalengka dengan konsep geotagging berbasis android, yang terdiri dari penjelasan penunjang aplikasi dan hasil pengecekan atau testing terhadap aplikasi yang telah dibuat, dimana pengujian terhadap aplikasi ini dilakukan dengan menggunakan pengujian Black Box Testing.

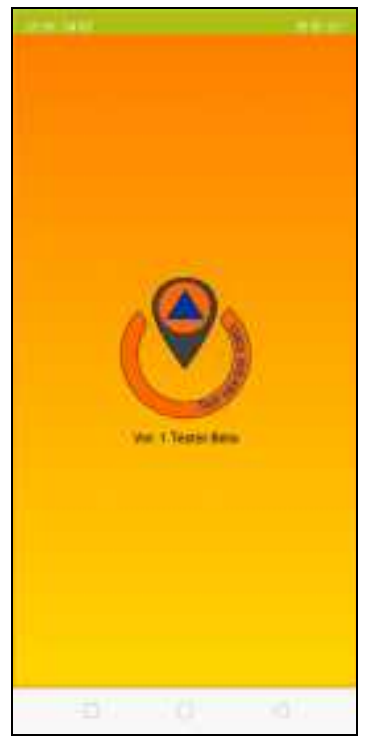

Gambar 5. Tampilan splash screen
Tampilan ini muncul setiap user membuka aplikasi tanda bencama apps, tampilan ini difungsikan untuk mempercantik aplikasi.

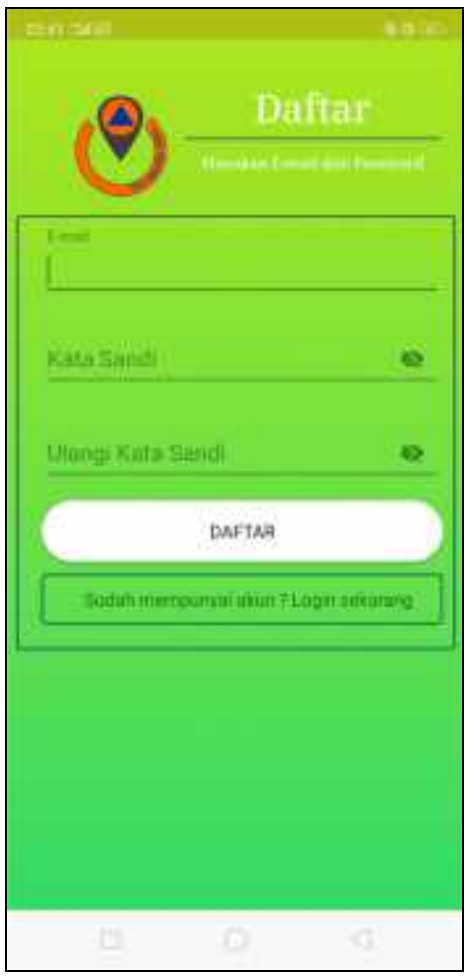

Gambar 6. Tampilan halaman pendaftaran baru

Form ini haruslah diakses terlebih dahulu ketika user belum mempunyai akun untuk login, setelah user mendaftarkan email dan password untuk login maka user akan secara otomatis langsung login menuju ke halaman ubah profile. 


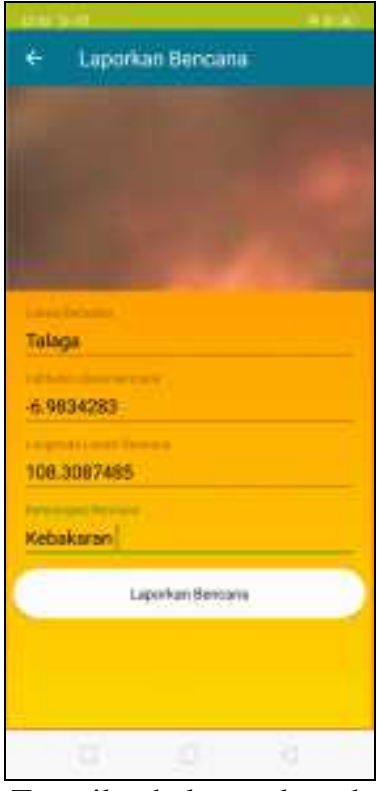

Gambar 7. Tampilan halaman laporkan bencana

Halaman untuk melaporkan bencana ketika user berada pada lokasi bencana, user harus mengambil foto bencana pada saat itu juga, ketika user mengambil foto, nama lokasi dan koordinat lokasi akan otomatis terisi mengambil titik foto tersebut diambil, kemudian masukan keterangan mengenai bencana.

\section{KESIMPULAN}

Dibuatnya aplikasi Tanda Bencana yang berbasis andorid ini bisa mencapai semua kalangan pengguna android sehingga bisa mudah digunakan untuk penyampaian informasi terkait perihal bencana di Kabupaten Majalengka;

Sangat membantu dalam penyampaian informasi bencana, sehingga masyarakat dapat mengirim informasi terjadinya bencana ke petugas terkait di Majalengka secara akurat dan detail melalui smartphone, user bisa secara detail memberikan laporan bencana karena memberikan foto, nama lokasi, koordinat, dan keterangan mengenai bencana karena telah menerapkan konsep geotagging, dengan dukungan database firebase penyampaian informasi perihal kebencanaan dapat dilakukan secara realtime dengan media penyimpanan yang bersifat aman, sehingga prosedur tanggap darurat bencana dapat dilaksanakan oleh petugasa terkait.

\section{REFERENSI}

[1] MZ, Halili. 2017. Aplikasi Rekomendasi Spot Area Wisata Berbasis Android dengan Teknik Geotag. Inform Journal Vol. 2 No.1

[2] Counter, S. 2018, presentasi pengguna android, http://gs.statcounter.com/os-marketshare/mobile/indonesia, diakses tanggal 28 Juli 2018
[3] BNPB. 2018, Definisi Bencana, https://bnpb.go.id/home/definisi, Diakses tanggal: 28 Juli 2018.

[4] Undang-undang Nomor 24 Tahun 2007

[5] Fitriansyah, dkk. 2013, Aplikasi Mobile Penanganan Bencana Dan Keadaan Darurat Berbasis Prosedur Dan Objek Pendukung, Jurnal Dasi, Vol. 14

[6] Fariza, dkk. 2013, Sistem Tanggap Darurat Untuk Manajemen Bencana Menggunakan Software Oriented Arsitektur, Prosiding Conference on SmartGreen Technology in Electrical and Information Systems.

[7] Hendri, dkk. 2016, RANCANG BANGUN AUTOMATIC EMERGENCY SYSTEM BERBASIS MOBILE, Seminar Nasional Sistem Informasi Indonesia.

[8] Rohmat, 2017, Rancang Bangun Implementasi Sistem Tanggap Darurat Bencana Menggunakan Firebase Cloud Messaging Berbasis Android Dan Sms Gateway.

[9] Ariansyah, dkk. 2015, Rancang Bangun Sistem Informasi Tanggap Darurat 